\title{
Assigned Cotactic Parameters in the Radical Copolymerization of Methyl Methacrylate with Various Methacrylates
}

\author{
Koichi Hatada, Tatsuki KitAYAMA, Takatoshi OCHI, \\ and Heimei YUKI \\ Department of Chemistry, Faculty of Engineering Science, \\ Osaka University, Toyonaka, Osaka 560, Japan
}

(Received April 8, 1987)

\begin{abstract}
Copolymers of totally deuterated methyl methacrylate with a small amount of various methacrylates were radically prepared in toluene and, if necessary, converted into the copolymer of MMA- $d_{8}$ with MMA. The assigned coisotactic parameters, $\sigma_{12}$ and $\sigma_{21}$, were determined from their ${ }^{1} \mathrm{H}$ NMR spectra. The values for the copolymerizations with triarylmethyl methacrylates $\left(\mathbf{M}_{2}\right)$ such as triphenylmethyl, diphenyl-2-pyridylmethyl or phenyl-2-pyridyl-otolylmethyl methacrylates, were unequivocally different from each other. The results indicated that the addition of $\mathrm{M}_{2}$ to MMA radical end favored syndiotactic placement while the addition of MMA to $\mathbf{M}_{2}$ end occurred preferentially in isotactic way. The cause of this peculiar stereoregulation in radical polymerization was discussed in detail.
\end{abstract}

KEY WORDS Radical Copolymerization / Cotacticity / Cotactic Parameter / Cross Propagation/Triphenylmethyl Methacrylate/ Methyl Methacrylate Deuterated / NMR / Heterotactic Copolymer / Isotactic Propagation /

The compositional and configurational analyses of copolymer give us an essential knowledge about not only characteristics of the copolymer itself but also mechanism of copolymerization. Configurational sequences, so-called cotacticity, of methacrylate copolymers have been studied well in connection with their stereoregular polymerization by radical and anionic initiators, ${ }^{1-6}$ partly because of the easiness in conversion of the copolymers to poly(methyl methacrylate) (PMMA) whose tacticity determination had been established. To elucidate stereoregulation in cross propagation step in copolymerization, at least two independent parameters, $\sigma_{12}$ and $\sigma_{21}$, should be taken into consideration. Here, $\sigma_{i j}$ is the probability of generating a meso dyad when a monomer unit $M_{j}$ is formed at the $M_{i}$ end of a growing chain as proposed by Bovey and Tiers. ${ }^{7}$ In the reports ${ }^{1-6}$ mentioned above, however, the two configurational parameters were assumed to be equal. The assumption had been unavoidable even if the NMR signals of methylene protons show splittings due to tacticity, since the methylene units in polymer chain can be hardly assigned to particular monomeric unit as easily recognized from the following formula. Klesper et al. ${ }^{8-10}$ investi-

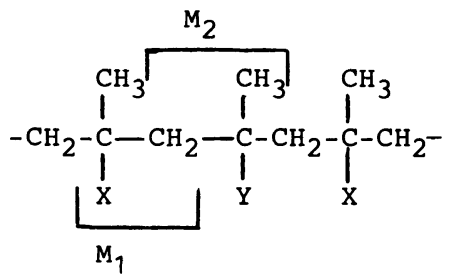

gated the configurational parameters in the radical copolymerizations of methyl methacrylate(MMA)-methacrylic acid, MMApentadeuteromethacrylic acid and pentadeuteromethyl methacrylate-methacrylic acid, and evaluated the parameters in cross prop- 
agation, $\Sigma_{\mathrm{s}}=\sigma_{12}+\sigma_{21}$ and $\Sigma_{\mathrm{p}}=\sigma_{12} \times \sigma_{21}$. From their results it was possible to determine the unassigned numerical values for $\sigma_{12}$ and $\sigma_{21}$, but these could not be assigned with their NMR data alone.

In the present work, totally deuterated MMA $\left(M_{1}\right)$ was radically copolymerized with a small amount of undeuterated methacrylate $\left(\mathrm{M}_{2}\right)$ so that most of $\mathrm{M}_{2}$ units in the copolymer were considered to be located in $\mathbf{M}_{1} \mathbf{M}_{2} \mathbf{M}_{1}$ sequence. The methylene proton signals in its ${ }^{1} \mathrm{H}$ NMR spectrum reflect stereochemical process in the addition of $\mathrm{M}_{2}$ monomer to $\mathrm{M}_{1}$ radical. Therefore, the analysis of the signals may lead us to the determination of the assigned cotactic parameters. Among the methacrylates examined, a series of triarylmethyl methacrylates had unequivocally different values of $\sigma_{12}$ and $\sigma_{21}$, revealing that the addition of these bulky methacrylates to MMA radical end proceeds in syndiotactic way but the addition of MMA to these methacrylate radicals occurs in isotactic manner. One of such peculiar cases had been previously reported shortly. ${ }^{11}$

\section{EXPERIMENTAL}

MMA was obtained commercially. MMA$d_{8}$ was prepared from acetone cyanohydrin- $d_{7}$ and methanol- $d_{4}$ according to the procedure of Crawford. ${ }^{12}$ The MMAs were purified by fractional distillation under reduced nitrogen pressure, dried over calcium hydride and then distilled again under high vacuum. Degree of deuteration of MMA- $d_{8}$ was determined by an NMR coaxial tubing method ${ }^{10}: \alpha$ $\mathrm{CD}_{3}, 99.7 \%$; $\mathrm{CD}_{2}, 99.7 \% ; \mathrm{OCD}_{3}, 99.8 \%$.

Triphenylmethyl, ${ }^{14}$ diphenyl-2-pyridylmethyl, ${ }^{15}$ phenyl-2-pyridyl-o-tolylmethyl, ${ }^{16}$ diphenylmethyl, ${ }^{17}$ 1-phenylethyl, ${ }^{18}$ and furfuryl ${ }^{19}$ methcacrylates were prepared by the procedures described in the literatures. Benzyl methacrylate was a commercial product. These monomers were purified by recrystallization or distillation.
Polymerization was carried out in a sealed glass ampoule under dried nitrogen atmosphere at $60^{\circ} \mathrm{C}$. The reaction mixture was poured into a large amount of methanol and the precipitated polymer was collected by filtration, washed with methanol and dried in vacuo at $50^{\circ} \mathrm{C}$.

Copolymers of MMA- $d_{8}$ with triarylmethyl methacrylates were treated with methanolic $\mathrm{HCl}$ to selectively hydrolyze the triarylmethyl esters. The resultant copolymers were reacted with diazomethane ${ }^{20}$ to convert the acid residue to methyl ester. The copolymers of MMA- $d_{8}$ with diphenylmethyl and 1-phenylethyl methacrylates were also converted to the copolymer of MMA- $d_{8}$ and MMA by the treatment with $\mathrm{HBr}$ gas followed by methylation with $\mathrm{CH}_{2} \mathrm{~N}_{2} \cdot{ }^{21}$ In order to check the possibility of deuterium-hydrogen exchange in MMA- $d_{8}$ unit during the acid hydrolysis, a poly(MMA- $\left.d_{8}\right)$ prepared with AIBN in toluene at $60^{\circ} \mathrm{C}$ was treated under the acid hydrolysis conditions. The intensity of ${ }^{1} \mathrm{H}$ NMR signal from $\alpha$-methyl group in the polymer increased $10 \%$ from that of the original polymer after the treatments, while the intensity from methylene group did not change. The similar changes of $\alpha$-methyl and methylene signals from MMA- $d_{8}$ unit in the copolymers may not affect the results of NMR analysis because the contribution of these signals were very small as being described in the results section. Other copolymers were directly subjected to NMR measurements.

The ${ }^{1} \mathrm{H}$ NMR spectra were measured in nitrobenzene- $d_{5}$ at $110^{\circ} \mathrm{C}$ on a JNM-FX100 Fourier transform NMR spectrometer (JEOL) at $100 \mathrm{MHz}$. Hexamethyldisiloxane (HMDS) was used as an internal standard.

\section{RESULTS}

Copolymerizations of totally deuterated methyl methacrylate (MMA- $d_{8}$ ) with $3 \mathrm{~mol} \%$ of a series of undeuterated methacrylates $\left(\mathrm{M}_{2}\right)$ were carried out in toluene at $60^{\circ} \mathrm{C}$ for $5 \mathrm{~h}$ 
Table I. Copolymerization of MMA- $d_{8}\left(\mathrm{M}_{1}\right)$ with a small amount of methacrylate $\left(\mathrm{M}_{2}\right)$ in toluene at $60^{\circ} \mathrm{C}$ by AIBN

\begin{tabular}{lcc}
\hline Methacrylate $\left(\mathrm{M}_{2}\right)$ & $\begin{array}{r}\text { Polymer } \\
\text { yield/\% }\end{array}$ & $\begin{array}{c}\text { Content of } \\
\text { MMA-d } / \mathrm{mol}_{\mathbf{8}} \%\end{array}$ \\
\hline Methyl & 75.1 & 96.8 \\
Benzyl & 42.8 & 96.1 \\
Furfuryl & 41.8 & 96.1 \\
1-Phenylethyl & 40.5 & 96.3 \\
Diphenylmethyl & 42.9 & 96.6 \\
Triphenylmethyl & 43.0 & 96.5 \\
Diphenyl-2-pyridyl- & 75.9 & 95.5 \\
$\quad$ methyl & & \\
Phenyl-2-pyridyl- & 77.7 & 96.5 \\
$\quad$ o-tolylmethyl & & \\
\hline
\end{tabular}

a $\mathrm{MMA}-d_{8}, \quad 8.6-8.9 \mathrm{mmol} ; \quad\left[\mathrm{MMA}-d_{8}\right] /\left[\mathrm{M}_{2}\right]=97 / 3$; AIBN, $1 \mathrm{~mol} \%$; toluene, $10 \mathrm{ml}$.

using AIBN as an initiator. The results are shown in Table I. The contents of the $\mathbf{M}_{2}$ units in the copolymers were determined by an NMR coaxial tubing method. Each copolymer contained about $4 \mathrm{~mol} \%$ of $\mathrm{M}_{2}$ units. It was estimated from monomer reactivity ratios that more than $92 \%$ of $\mathrm{M}_{2}$ units was in the sequence of $\mathbf{M}_{1} \mathbf{M}_{2} \mathbf{M}_{1}$ triad. As the first approximation, contributions from the other $\mathbf{M}_{2}$ centered triads were neglected. The validity of this assumption will be discussed later. Now, the intesities of the $\alpha$-meth-<smiles>[R]OC(=O)C(C)(CC(C)(C)[13C](=O)[O-])C(=O)O[13C](=O)[O-]</smiles>

$$
M_{1} M_{2} M_{1} \operatorname{triad}
$$

yl proton signals due to isotactic, heterotactic, and syndiotactic triads of the above sequence can be expressed as functions of $\sigma_{12}$ and $\sigma_{21}$.

$$
\begin{aligned}
I & =\sigma_{12} \times \sigma_{21} \\
H & =\sigma_{12}\left(1-\sigma_{21}\right)+\sigma_{21}\left(1-\sigma_{12}\right) \\
S & =\left(1-\sigma_{12}\right) \times\left(1-\sigma_{21}\right)
\end{aligned}
$$

From these equations, a set of the unassigned coisotactic parameters were derived. On the

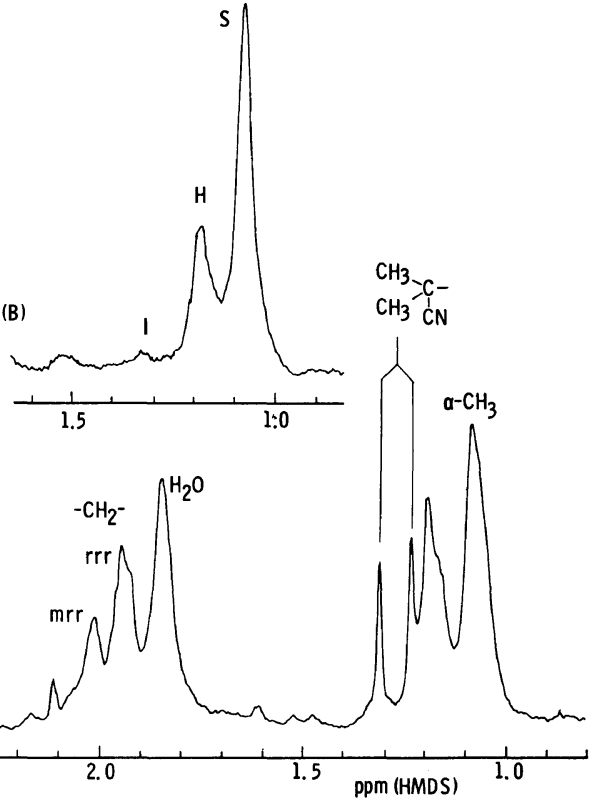

Figure 1. ${ }^{1} \mathrm{H}$ NMR spectra of the copolymer of MMA- $d_{8}$ with MMA derived from the copolymer of MMA- $d_{8}$ with diphenylmethyl methacrylate: (A) normal spectrum; (B) partially relaxed spectrum (pulse sequence, $180^{\circ}-0.6 \mathrm{~s}-90^{\circ}-10 \mathrm{~s}$ ). (Nitrobenzene- $d_{5}, 110^{\circ} \mathrm{C} ; 100$ scans, $100 \mathrm{MHz}$ ).

other hand, the resonances in the backbone methylene region should give information on the value of $\sigma_{12}$, since the methylene protons originated from $\mathrm{M}_{2}$ monomer. However, due to poor separation and complicated spectral pattern in this region, it seemed better to derive quantitative data of cotactic parameters from the $\alpha$-methyl proton signals using eq $1-$ 3 . When there is a substantial difference between $\sigma_{12}$ and $\sigma_{21}$, the information on the tacticity from the methylene signals may permit us to select $\sigma_{12}$ from the set of unassigned parameters.

As mentioned in the experimental section, most of the copolymers were converted to the copolymers of MMA- $d_{8}$ and MMA through selective ester hydrolysis of $\mathbf{M}_{2}$ unit followed by the subsequent methylation. Two typical ${ }^{1} \mathrm{H}$ NMR spectra of the derived copolymers from the copolymers of MMA- $d_{8}$ with diphen- 
ylmethyl (DPMMA) and triphenylmethyl (TrMA) methacrylates are shown in Figures 1 and 2 , respectively. In both spectra, the isotactic and heterotactic $\alpha-\mathrm{CH}_{3}$ signals were overlapped with peaks for the initiator fragment, $\left(\mathrm{CH}_{3}\right)_{2} \mathrm{C}(\mathrm{CN})-{ }^{22}$ The spin-lattice relaxation time $\left(T_{1}\right)$ of the latter signals $(1.0 \mathrm{~s})$ was longer enough than those for $\alpha-\mathrm{CH}_{3}$ protons $(0.25$ $0.3 \mathrm{~s}$ ) so that the peaks could be eliminated in the partially relaxed spectra (Figures $1(B)$ and 2(B)) taken at an optimized pulse interval between $180^{\circ}$ and $90^{\circ}$ pulses as described in the figure captions. On the other hand, the residual protons in the $\alpha$-methyl group of MMA$d_{8}$ unit also overlapped with the $\mathrm{CH}_{3}$ signals of MMA unit derived from $\mathrm{M}_{2}$ units. The $T_{1}$ value of the remaining hydrogen, $\mathrm{CHD}_{2}$, in radically prepared polymer of MMA- $d_{8}$ was about $2.5 \mathrm{~s}$. Since the contents of MMA- $d_{8}$ units in the copolymers examined in this study were over $96 \%$, most of the $\mathrm{CHD}_{2}$ hydrogen in the MMA- $d_{8}$ units are safely assumed to have the same $T_{1}$ value as that in the homopolymer of MMA- $d_{8}$. From this assumption, the intensity of $\mathrm{CHD}_{2}$ signals in the partially relaxed spectra shown in Figures 1(B) and 2(B) could be calculated to be negative and $60 \%$ of that in the normal spectra. This negative contribution was subtracted from the spectra by considering the degree of deuteration of $\alpha$-methyl hydrogens in MMA- $d_{8}$ monomer used and the content of MMA- $d_{8}$ units in each copolymer. For example, uncorrected values for the copolymer derived from the copolymer of MMA- $d_{8}$ with TrMA were $I=6.4 \%, H=$ $63.5 \%$, and $S=30.1 \%$. These values deviated only slightly from the corrected ones $(I=6.3$, $H=62.0, S=31.7)$. The corrected and uncorrected values for the copolymer of MMA$d_{8}$ and DPMMA (Figure 1) were almost identical since the observed triad tacticity was close to that of PMMA. Even if the intensity change of $\alpha$-methyl group in MMA$d_{8}$ unit caused by hydrolysis ocurred in the case of the copolymer, this will give rise to negligibly small deviation in the tacticity $(I=$
6.3, $H=61.9, S=31.8$ ). Therefore, the effect of deuterium-hydrogen exchange was neglected in the calculation of cotactic parameters.

Triad tacticity of the copolymers was determined from the above procedure. By introducing these values into eq 1,2 , and 3 , a set of values for $\sigma_{12}$ and $\sigma_{21}$ were calculated as shown in Table II. In the cases of the copolymerizations with benzyl, furfurtyl, 1-phenylethyl or diphenylmethyl methacrylates, derived copolymers of MMA- $d_{8}$, and MMA showed ${ }^{1} \mathrm{H}$ NMR spectrum typical for syndiotactic PMMA as in Figure 1. Coisotactic parameters in these copolymerizations were close to each other and also to meso dyad fraction, $\sigma_{22}$, of homopolymers of $\mathrm{M}_{2}$ monomers. This made it difficult to judge which value should be assigned to $\sigma_{12}$ or $\sigma_{21}$ from methylene proton signals. Moreover, the cotactic parameters for these cases are affected sensitively by a slight change in the triad tacticity as evidenced from the data for benzyl and 1-phenylethyl methacrylates. Therefore, the assignment was left undone for these cases. Also, it is not clear whether the differences between $\sigma_{12}$ and $\sigma_{21}$ are meaningful or not.

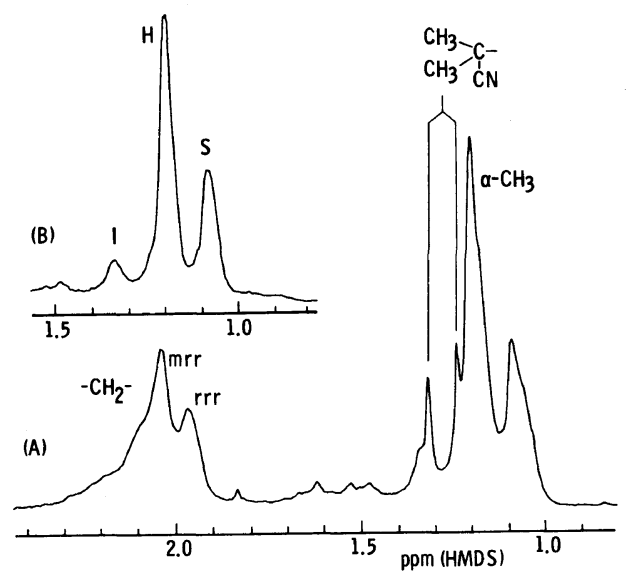

Figure 2. ${ }^{1} \mathrm{H}$ NMR spectra of the copolymer of MMA- $d_{8}$ with MMA derived from the copolymer of MMA- $d_{8}$ with triphenylmethyl methacrylate: (A) normal spectrum; (B) partially relaxed spectrum (pulse sequence, $\left.180^{\circ}-0.6 \mathrm{~s}-90^{\circ}-10 \mathrm{~s}\right)$. (Nitrobenzene- $d_{5}, 110^{\circ} \mathrm{C} ; 100 \mathrm{scans}$, $100 \mathrm{MHz}$ ). 
The $\mathbf{M}_{2}$ centered triad tacticity in the copolymer of MMA- $d_{8}$ with TrMA, diphenyl-2pyridylmethyl (DPyMA), or phenyl-2-pyridyl$o$-tolylmethyl methacrylate (PPyTMA) was predominantly heterotactic as represented in Figure 2. Heterotactic triad contents for $\mathbf{M}_{2}$ centered sequence in these copolymers exceeded $65 \%$. Derived values for $\sigma_{12}$ and $\sigma_{21}$ were unequivocally different from each other, one exceeded 0.5 and the other less than 0.5. As seen in Figure 2(A), methylene proton signals due to MMA unit in the copolymer derived from the copolymer of MMA- $d_{8}$ and TrMA were typical for syndiotactic PMMA, indicating the predominance of racemo placement between MMA- $d_{8}$ and TrMA units in the original copolymer. Therefore, the coisotactic parameter for the sequence of MMA- $d_{8}$ to TrMA should be less than 0.5 , and the smaller value $(0.10)$ could be assigned to $\sigma_{12}$ and the larger to $\sigma_{21}$. Similar results were obtained for the copolymerizations of $\mathrm{MMA}-d_{8}$ with DPyMA and PPyTMA.

MMA was copolymerized with MMA- $d_{8}$ and the triad tacticity for MMA centered triad was analyzed to give cotactic parameters. As seen in Table II, $\sigma_{12}$ and $\sigma_{21}$ were similar to each other and also to the meso dyad for the homopolymer of PMMA. this consistency indicates the validity of evaluation of coisotactic parameters from the copolymerization of deuterated monomer with undeuterated monomer.

As mentioned above, in the copolymerization of MMA with triarylmethyl methacrylate, $\mathbf{M}_{1} \mathbf{M}_{2} \mathbf{M}_{1}$ triad was predominantly heterotactic. Accordingly, the copolymer containing these alternating sequence in a substantial amount should be rich in heterotactic content as a whole. Following this idea, copolymerizations of MMA with DPyMA at varying monomer feed ratios were carried out in

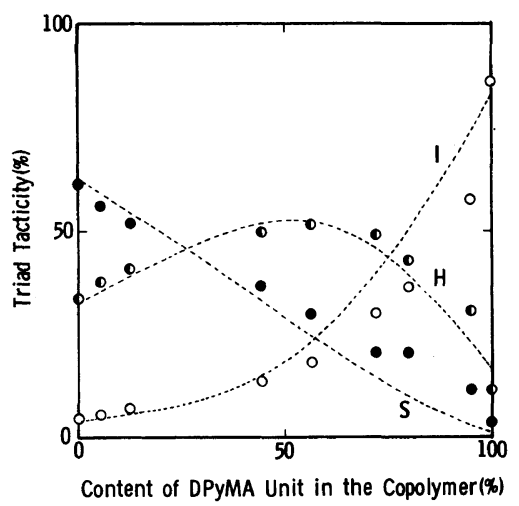

Figure 3. Triad tacticity of PMMA derived from copolymers of MMA with diphenyl-2-pyridylmethyl methacrylate (DPyMA): $\bigcirc$, isotactic; $D$, heterotactic; O, syndiotactic triad. Dotted lines indicate calculated values by using following data: $r_{1}=0.40 ; r_{2}=0.72$; $\sigma_{11}=0.21 ; \sigma_{12}=0.11 ; \sigma_{21}=0.66 ; \sigma_{22}=0.91$.

Table II. Triad tacticities and coisotactic parameters for the copolymers of MMA- $d_{8}\left(\mathrm{M}_{1}\right)$ and other methacrylates $\left(\mathbf{M}_{2}\right)$

\begin{tabular}{|c|c|c|c|c|c|c|}
\hline \multirow{2}{*}{$\begin{array}{l}\text { Methacrylate } \\
\qquad \mathbf{M}_{2}\end{array}$} & \multicolumn{3}{|c|}{ Tacticity $/ \%$ a } & \multicolumn{3}{|c|}{ Coisotactic parameter ${ }^{b}$} \\
\hline & $I$ & $H$ & $S$ & $\sigma_{12}$ & $\sigma_{21}$ & $\sigma_{22}$ \\
\hline Methyl & 4.4 & 33.2 & 62.4 & $(0.20$ & $0.22)$ & 0.21 \\
\hline Benzyl & 3.9 & 34.3 & 61.7 & $(0.14$ & $0.28)$ & 0.25 \\
\hline Furfuryl & 4.2 & 31.8 & 64.0 & $(0.20$ & $0.20)$ & 0.26 \\
\hline 1-Phenylethyl & 4.7 & 34.2 & 61.1 & $(0.19$ & $0.24)$ & 0.24 \\
\hline Diphenylmethyl & 5.2 & 36.0 & 58.8 & $(0.19$ & $0.27)$ & 0.23 \\
\hline Triphenylmethyl & 6.3 & 62.0 & 31.7 & 0.10 & 0.65 & 0.75 \\
\hline Diphenyl-2-pyridylmethyl & 7.7 & 62.6 & 29.7 & 0.11 & 0.66 & 0.92 \\
\hline Phenyl-2-pyridyl-o-tolylmethyl & 6.7 & 65.2 & 28.1 & 0.10 & 0.69 & 0.84 \\
\hline
\end{tabular}

a Tacticity of $\mathbf{M}_{2}$ centered triad sequence.

b Pairs of values in parentheses were not assigned to either parameter. 


\section{K. HATAda et al.}

toluene at $60^{\circ} \mathrm{C}$. Yields in weight ranged from 8 to $12 \%$. Monomer reactivity ratio was determined by Fineman-Ross plot; $r_{1}=0.4, r_{2}=$ 0.72 . Figure 3 shows triad tacticities of PMMA's derived from the copolymers. The copolymer containing $56 \mathrm{~mol} \%$ of DPyMA unit had the highest heterotacticity of $51.7 \%$, which can be named heterotactic-rich polymer because the highest heterotacticity in completely random stereoreguration is $50 \%$. Dotted lines in the figure show calculated tacticity based on the values of $r_{1}, r_{2}, \sigma_{11}, \sigma_{12}$, $\sigma_{21}, \sigma_{22}$, and monomer feed. Discrepancy between the calculated and observed tacticities indicates the effect of penultimate or farther units on the stereoregulation. At high DPyMA feed, in particular, incorporation of a small amount of MMA decreased the isotacticity more drastically than expected.

\section{DISCUSSION}

In the radical copolymerization of MMA- $d_{8}$ with the methacrylates excluding triarylmethyl methacrylates, stereoregularities of $\mathbf{M}_{2}$ centered triad were syndiotactic as the cases of the homopolymerizations of $\mathbf{M}_{2}$ monomers and MMA. There was little or no difference between $\sigma_{12}$ and $\sigma_{21}$. Accordingly, it is rather difficult at present to distinguish these two coisotactic parameters and to assign them to $\sigma_{12}$ or $\sigma_{21}$ from the methylene proton signals.

In contrast to the above cases, $\mathbf{M}_{2}$ units in the copolymers of MMA- $d_{8}$ with three kinds of triarylmethyl methacrylates were predominantly in heterotactic triad sequence. The derived values for $\sigma_{12}$ and $\sigma_{21}$ indicate that the configurational parameters in cross propagation are different from each other in these
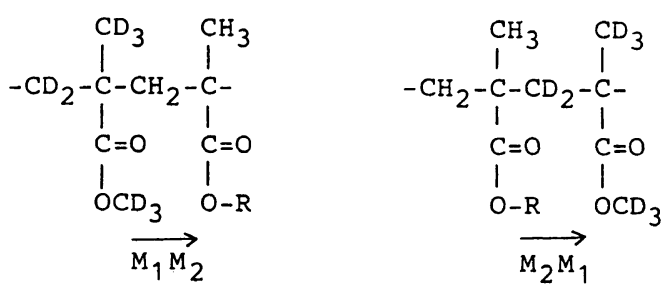

copolymerizations. The methylene signals revealed that the sequence of MMA- $d_{8}$ to $\mathbf{M}_{2}$ $\left(\overrightarrow{M_{1} M_{2}}\right)$ was predominantly racemo dyad and that of $\mathrm{M}_{2}$ to MMA-d $\left(\overrightarrow{\mathrm{M}_{2} \mathrm{M}_{1}}\right)$ meso dyad. The results show that the structure of the radical end is one of the important factor for the stereoregulation in the propagation reaction. While most of methacrylates are polymerized to syndiotactic polymer by radical initiator, these triarylmethyl methacrylates give isotactic polymers in the radical polymerization as well as in the anionic polymerization. ${ }^{15-17,25}$ Kamachi et al. suggested from their ESR study that TrMA radical at the growing chain end in its radical homopolymerization has more rigid conformation than the PMMA radical. ${ }^{23,24}$ The results obtained in this study strongly indicate that the triarylmethyl methacrylate radicals have also rigid conformation, preserving the stereochemical nature, even if they are located alone at the end of fairly long chain of MMA. On the other hand, the isotactic parameters for the homopolymers of triarylmethyl methacrylates, $\sigma_{22}$, are higher than $\sigma_{21}$ 's, indicating the higher stereoregulation in the addition of triarylmethyl methacrylates to their radical ends than in the addition of MMA.

For the copolymerization systems, excluding that of PPyTMA, the tacticity for $\mathbf{M}_{2}$ centered triad, i.e., $\overrightarrow{\mathrm{M}_{1} \mathrm{M}_{2} \mathrm{M}_{1}}, \quad \mathrm{M}_{1} \mathrm{M}_{2} \mathrm{M}_{2}$, $\overrightarrow{M_{2} M_{2} M_{1}}$, and $M_{2} M_{2} M_{2}$, was calculated with
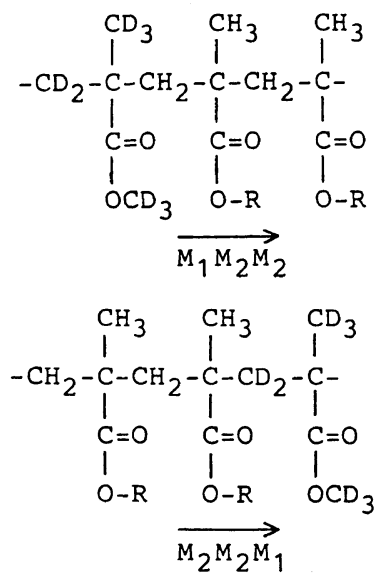
Cotactic Parameter in Copolymn. of Methacrylates

Table III. Estimated cotacticity of $\mathbf{M}_{2}$ centered triad

\begin{tabular}{|c|c|c|c|c|c|c|c|}
\hline \multirow{2}{*}{$\begin{array}{l}\text { Methacrylate } \\
\qquad \mathbf{M}_{2}\end{array}$} & \multirow{2}{*}{$\begin{array}{l}r_{1} \\
r_{2}\end{array}$} & \multirow{2}{*}{$\frac{\mathbf{M}_{2} \text { content }}{\%}$} & \multirow{2}{*}{\multicolumn{2}{|c|}{ Triad $^{\mathrm{a}}$}} & \multicolumn{3}{|c|}{ Cotacticity $/ \%$ b } \\
\hline & & & & & $I$ & $H$ & $S$ \\
\hline \multirow[t]{4}{*}{ Benzyl } & $0.93^{26}$ & 3.8 & $\mathrm{M}_{1} \mathrm{M}_{2} \mathbf{M}_{1}^{\mathrm{c}}$ & (3.5) & 3.9 & 34.3 & 61.7 \\
\hline & $1.05^{26}$ & & $\overrightarrow{\mathrm{M}_{1} \mathrm{M}_{2} \mathrm{M}_{2}}$ & $(0.15)$ & 2.8 & 28.6 & 68.6 \\
\hline & & & $\mathbf{M}_{2} \mathbf{M}_{2} \mathbf{M}_{1}$ & $(0.15)$ & 5.6 & 36.8 & 57.6 \\
\hline & & & Average & & 4.0 & 34.2 & 61.8 \\
\hline \multirow[t]{4}{*}{ Furfuryl } & $0.75^{27}$ & 3.9 & $\mathbf{M}_{1} \mathbf{M}_{2} \mathbf{M}_{1}{ }^{\mathrm{c}}$ & (3.7) & 4.2 & 31.8 & 64.0 \\
\hline & $1.19^{27}$ & & $\overrightarrow{\mathrm{M}_{1} \mathrm{M}_{2} \mathrm{M}_{2}}$ & $(0.13)$ & 4.6 & 33.8 & 61.6 \\
\hline & & & $\mathrm{M}_{2} \mathrm{M}_{2} \mathrm{M}_{1}$ & $(0.13)$ & 4.6 & 33.8 & 61.6 \\
\hline & & & Average & & 4.0 & 32.1 & 63.8 \\
\hline \multirow[t]{4}{*}{ 1-Phenylethyl } & $0.81^{6}$ & 3.6 & $\mathbf{M}_{1} \mathbf{M}_{2} \mathbf{M}_{1}{ }^{\mathrm{c}}$ & (3.4) & 4.7 & 34.2 & 61.1 \\
\hline & $0.92^{6}$ & & $\overrightarrow{\mathrm{M}_{1} \mathrm{M}_{2} \mathrm{M}_{2}}$ & $(0.10)$ & 4.7 & 34.1 & 61.2 \\
\hline & & & $\mathrm{M}_{2} \mathrm{M}_{2} \mathrm{M}_{1}$ & $(0.10)$ & 5.8 & 36.5 & 57.7 \\
\hline & & & Average & & 4.7 & 34.3 & 61.0 \\
\hline \multirow[t]{4}{*}{ Diphenylmethyl } & $0.81^{6}$ & 3.7 & $\mathbf{M}_{1} \mathbf{M}_{2} \mathbf{M}_{1}{ }^{\mathrm{c}}$ & (3.4) & 5.2 & 36.0 & 58.8 \\
\hline & $1.07^{6}$ & & $\overrightarrow{\mathrm{M}_{1} \mathrm{M}_{2} \mathrm{M}_{2}}$ & $(0.11)$ & 4.5 & 33.8 & 61.6 \\
\hline & & & $\overrightarrow{\mathrm{M}_{2} \mathrm{M}_{2} \mathrm{M}_{1}}$ & $(0.11)$ & 6.6 & 38.3 & 55.1 \\
\hline & & & Average & & 5.2 & 36.0 & 58.8 \\
\hline \multirow[t]{4}{*}{ Triphenylmethyl } & 0.92 & 3.3 & $\mathbf{M}_{1} \mathbf{M}_{2} \mathbf{M}_{1}^{\mathrm{c}}$ & $(3.0)$ & 6.3 & 62.0 & 31.7 \\
\hline & 1.20 & & $\overrightarrow{\mathrm{M}_{1} \mathrm{M}_{2} \mathrm{M}_{2}}$ & $(0.11)$ & 7.3 & 70.1 & 22.6 \\
\hline & & & $\overrightarrow{M_{2} M_{2} M_{1}}$ & $(0.11)$ & 48.7 & 42.5 & 8.8 \\
\hline & & & Average & & 7.9 & 61.6 & 30.5 \\
\hline \multirow[t]{4}{*}{ Diphenyl-2-pyridylmethyl } & 0.40 & 6.8 & $\mathbf{M}_{1} \mathbf{M}_{2} \mathbf{M}_{1}{ }^{\mathrm{c}}$ & $(6.5)$ & 7.7 & 62.6 & 29.7 \\
\hline & 0.72 & & $\overrightarrow{\mathrm{M}_{1} \mathrm{M}_{2} \mathrm{M}_{2}}$ & $(0.15)$ & 10.6 & 81.5 & 8.0 \\
\hline & & & $\overrightarrow{\mathrm{M}_{2} \mathrm{M}_{2} \mathrm{M}_{1}}$ & $(0.15)$ & 60.4 & 36.6 & 3.0 \\
\hline & & & Average & & 8.9 & 62.4 & 28.7 \\
\hline
\end{tabular}

a Figures in parentheses are contents in percentage of each triad in the copolymers.

b The smaller value in each set of coisotactic parameters was tentatively assigned to $\sigma_{12}$ in these calculations.

c Observed cotacticity.

monomer reactivity ratios, monomer feed ratios, and cotactic parameters obtained in this work and $\sigma_{22}$. Results are summarized in Table III where the data for $\mathbf{M}_{2} \mathbf{M}_{2} \mathbf{M}_{2}$ triad are excluded because their fractions are less than 0.0001 .

For the copolymers of MMA- $d_{8}$ with methacrylates other than triarylmethyl methacrylates, the calculated tacticities for all $M_{2}$ centered triads were syndiotactic and the 


\section{K. Hatada et al.}

averaged values were almost identical to the observed ones. On the other hand, tacticities of $\overrightarrow{\mathbf{M}}_{1} \mathbf{M}_{2} \vec{M}_{2}$ and $\overrightarrow{\mathbf{M}}_{2} \mathbf{M}_{2} \vec{M}_{1}$ triads for the copolymers of MMA and triarylmethyl methacrylates were quite different from that for $\mathbf{M}_{1} \mathbf{M}_{2} \mathbf{M}_{1}$ triad. Moreover, a single parameter of $\sigma_{22}$ derived from the tacticity of the homopolymers is not enough to describe the configurational sequence in the strict sense, because stereoregularity of homopolymers of triarylmethyl methacrylates apparently do not obey Bernoullian statistics. Nevertheless, the average values calculated were very close to the observed ones. The results mean that the contribution of $\mathrm{M}_{2}$ centered triads other than $\mathbf{M}_{1} \mathbf{M}_{2} \mathbf{M}_{1}$ triad to the observed tacticity is negligibly small and the approximation employed for formulating the eq 1,2 , and 3 was acceptable.

Peculiar stereoregulation in the cross propagation step of radical copolymerization of

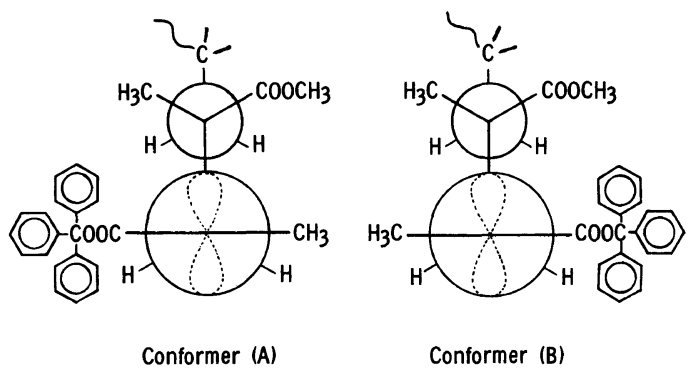

Figure 4. Model conformers of triphenylmethyl methacrylate radical end with a penultimate unit of MMA.
MMA with the triarylmethyl methacrylate was considered based on simplified models of chain end radicals as shown in Figures 4 and 5, where the case of TrMA was taken as an example. If we assume $s p^{2}$ carbon as the radical center, the dyad configuration of the MMA-TrMA sequence is fixed after the addition of the next monomer, in this case, MMA. In Figure 4, two probable conformers are illustrated in trans conformation along the main chain. If the attack of the next coming monomer occurs from the lower side of the radical center, the conformer (A) gives syndiotactic dyad while the conformer (B) gives isotactic dyad. The ester groups in the terminal and penultimate monomer units, which are bulkier than $\alpha$-methyl group, are separated farther in the conformer (A) than in the conformer (B). The experimental results require the more frequent addition of MMA onto the conformer (A) than to the conformer (B) and the above argument fits this requirement. Replacement of terminal TrMA unit by MMA unit, leading to the situation of homopolymerization of MMA, might decrease the preference of the conformer (A) over the conformer (B) and increase the isotacticity. This might explain the difference between $\sigma_{12}(0.10)$ and $\sigma_{11}(0.21)$. Direct determination of $\sigma_{12}$ from methylene signals will verify the difference and is under investigation by using an higher magnetic field NMR spectrometer.

Figure 5 illustrates the possible conformers
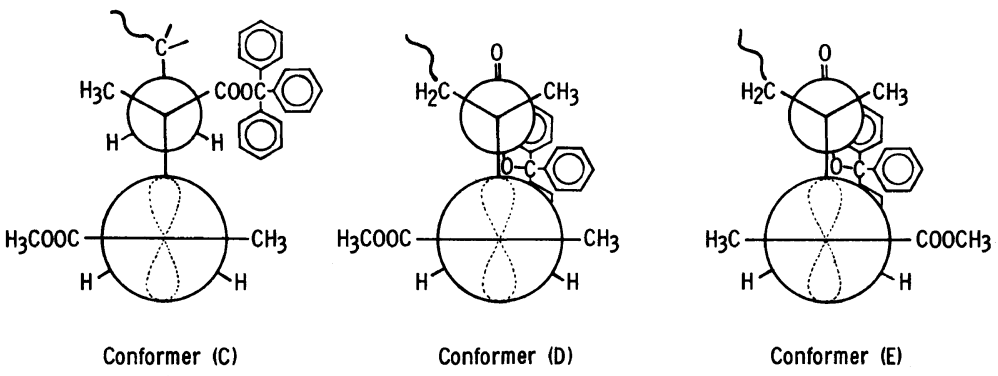

Figure 5. Model conformers of MMA radical end with a penultimate unit of triphenylmethyl methacrylate. 
for radical end of MMA with the penultimate TrMA unit. The main chain of conformer (C) is trans and two ester groups are spatially arranged in the form similar to that of the conformer (A). From this conformer, the addition of next monomer from the lower side gives syndiotactic placement. If the triarylmethyl ester in the penultimate unit is bulkier compared with the penpenultimate MMA unit in the chain, a gauche conformation along the main chain as in the the conformers (D) and (E) are preferable. In the conformer (D), the ester group in the terminal MMA unit locates farther from the penpenultimate MMA unit, while in the conformer (E) the group is placed near to the penpenultimate unit. Addition of next monomer from lower side of the conformer (D) should give isotactic dyad but the addition to the conformer (E) should not. The frequent addition to the conformer (D) fits the experimental results rather than the conformers (C) or (E). Highly isotactic polymer of TrMA prepared by chiral anionic initiator is proved to have helical structure in which the main chain has trans-gauche conformation to prevent steric hindrance due to the bulky ester group. In this connection, gauche conformation in the conformer (D) might be rationalized. If the terminal and penpenultimate units are also TrMA as the case of homopolymer of TrMA, preference of the conformer (D) over the conformer (E) might be emphasized to afford higher isotacticity.

Acknowledgment. The authors are grateful to Dr. M. Kamachi of Osaka University for his helpful discussion and Mr. Y. Kobayashi for experimental collaboration.

\section{REFERENCES}

1. K. Ito, T. Sugie, and Y. Yamashita, Makromol. Chem., 125, 291 (1969).
2. J. C. Bevington, D. O. Harris, and F. S. Raankin, Eur. Polym. J., 6, 725 (1970).

3. P. Vlcek, D. Doskocilova, and J. Trekoval, J. Polym. Sci., Polym. Symp., 42, 231 (1973).

4. A. Yamada and J. Tanaka, Preprint of 23rd Symposium of Polymer Science, Japan, Tokyo, 1974, p 253.

5. Y. Okamoto, S. Nakashima, K. Ohta, K. Hatada, and H. Yuki, J. Polym. Sci., Polym. Lett. Ed., 13, 273 (1975).

6. H. Yuki, Y. Okamoto, Y. Shimada, K. Ohta, and K. Hatada, J. Polym. Sci., Polym. Chem. Ed., 17, 1215 (1979).

7. F. A. Bovey and G. V. D. Tiers, Fortshr. Hochpolym. Forsch., 3, 139 (1963).

8. E. Klesper and W. Gronski, J. Polym. Sci., B7, 661 (1969).

9. E. Klesper, J. Polym. Sci., A-1, 8, 1191 (1970).

10. E. Klesper, A. Johnsen, W. Gronski, and F. W. Wehrli, Makromol. Chem., 176, 1071 (1975).

11. K. Hatada, T. Kitayama, K. Fujikawa, K. Ohta, and H. Yuki, Polym. Bull., 1, 97 (1978).

12. J. C. W. Crawford, Br. Patent, 405,699 (1934).

13. K. Hatada, Y. Terawaki, and H. Okuda, Org. Magn. Res., 9, 518 (1977).

14. N. A. Adrova and L. K. Prokhorova, Vysokomol. Soedin., Ser. A, 3, 1509 (1961).

15. Y. Okamoto, M. Ishikura, K. Hatada, and H. Yuki, Polym. J., 15, 851 (1983).

16. E. Yashima, Y. Okamoto, and K. Hatada, Polym. J., 19, 897 (1987).

17. H. Yuki, K. Hatada, T. Niinomi, and Y. Kikuchi, Polym. J., 1, 36 (1970).

18. H. Yuki, K. Ohta, Y. Ono, and S. Murahashi, $J$. Polym. Sci., A-1, 6, 829 (1968).

19. T. Ito, K. Aoshima, F. Toda, K. Uno, and Y. Iwakura, Polym. J., 1, 278 (1970).

20. A. Katchalsky and H. Eisenberg, J. Polym. Sci., 6, 145 (1951).

21. H. Yuki, K. Ohta, Y. Okamoto, and K. Hatada, Polym. J., 10, 505 (1978).

22. K. Hatada, T. Kitayama, and E. Masuda, Polym. J., 18, 395 (1986).

23. M. Kamachi, M. Kohno, D.-J. Liaw, and S. Katsuki, Polym. J., 10, 69 (1978).

24. M. Kamachi, Y. Kuwae, and S. Nozakura, Polym. J., 13, 919 (1981).

25. Y. Okamoto, K. Suzuki, K. Ohta, and H. Yuki, J. Am. Chem. Soc., 101, 4763 (1979).

26. J. C. Bevington and B. W. Malpass, Eur. Polym. J., 1, 85 (1965)

27. J. C. Bevington and D. O. Harris, J. Polym. Sci., B5, 799 (1967). 